this type of house. The party also visited a deserted village site below Hounds Tor which has recently been discovered by members of the Ordnance Survey. About twelve house sites, thought to be identified with seven or eight farms, are clearly visible from the rubble remains, but nothing is yet known of the date of settlement or of desertion; excavation on the site will start this summer.

On the second evening of the conference members heard a paper from Prof. Slicher van Bath, head of the Department of Rural History at Wageningen in the Netherlands. Prof. Slicher van Bath discussed the use of farm accounts as material for investigating farm management and agricultural output between the Middle Ages and the eighteenth century. $\mathrm{He}$ outlined the results of a study he had made of extant accounts in several countries, including those of the English early seventeenth-century farmer, Robert Loder of Harwell (Camden Third Series, 53, 1936).

On the last morning of the conference there were papers from Mr. J. Z. Titow of Cambridge and Prof. Beresford of Leeds. Mr. Titow discussed his recent work on the types of manors to be found on the Winchester estates in the thirteenth century. It had, he said, been assumed that the descent of villein property was mainly from father to son, but he produced substantial evidence to support a plea for considering more seriously the position of widows. On many of the Winchester manors it was clear that holdings were often left to the widow and that a kind of 'widow cycle of inheritance' was thus set up. A young man in search of a holding would therefore seek a widow with one. As a result of this a widow might remarry and leave the holding on her death to her second husband who in his turn remarried, leaving it on his death to his widow who might then marry again; direct descent to the eldest son appeared to be relatively uncommon.

Prof. Beresford set out some provisional ideas on the development of the unusual settlement pattern in fourteenth-century Cornwall. He explained that a great deal more work was required on Cornish settlement patterns, and that potential workers would be encouraged to know that from the material in the Duchy of Cornwall archives it was possible to trace the occupation of Duchy holdings from the fourteenth century to the early nineteenth. Dr. Hoskins, in his concluding remarks as chairman for Prof. Beresford, said he hoped members, as a result of the conference, would be more conscious of the need for work in south-west England and the rich material that awaited them. He was glad, too, that the Society had met in the highland zone, for, in his opinion, the British highlands had been neglected by agrarian historians.
J. W. Y. HIGGS

\title{
DISEASE TRANSMISSION BY TICKS
}

$\mathrm{T}$ HE papers presented at the recent sixth symposium of the Zoological Society of London on "Some Aspects of Disease Transmission by Ticks", held in London on March 8, revealed how some of the pieces of this complex jig-saw puzzle are gradually being filled in, but at the same time it was indicated that there are major deficiencies in our knowledge. Dr. J. MacLeod, by reference to a very interəsting mechanical analogue of the forces at work, showed that thy disease associations of ticks represent meshes in the food web of a biotic community which includes the pathogens, their tick vectors, the vertebrate hosts and the vegetational environment which supports and/or shelters them all. In this connexion it is worth noting that the physical relation. ships of tick distribution in Britain to the type of ground-cover are known for only one of the nineteen species of ticks; the biotic relationships, with two exceptions, are practically unknown. So far as British ticks are concerned, Ixodes ricinus has been the species most thoroughly investigated, principally because of its known disease relations. One of these diseases, Scottish louping ill, like other viruses of tick encephalitides, appears to have a casual rather than an intimate association with its hosts, which are principally sheep in Britain. Although the ease with which this disease can be transmitted by non. British ticks, for example, Rhipicephalus appendiculatus, suggests that any of the mammal-infesting British ticks would be capable of transmitting it to any British mammal; the infection has been demonstrated in $I$. ricinus from sheep in Nature, both by inoculation and infection.

Clinically, louping ill resembles poliomyelitis of man, and the virus multiplies primarily outside the central nervous system and during the fever, which precedes clinical signs, the pathogenic micro-organ- ism can be detected in the blood. Dr. W. S. Gordon's experimental results indicate that most sheep on a louping ill farm eventually become infected. Many develop only a fever, recover and are afterwards immune, but a small proportion develop clinical signs of infection of the central nervous system. In these cases lesions of an encephalomyelitis can be demonstrated and virus recovered from the brain and the spinal cord. On a world scale, according to Dr. C. E. Gordon Smith, there are thirteen known tick-borne animal viruses transmitted by five genera of hard ticks and one of soft ticks. All these viruses, except one, cause disease in man or domestic animals which are usually incidental hosts of the viruses. Their long-term natural maintenance depends on the geographical and behavioural association between vector tick and ground-frequenting mammal, and bird species, in the blood streams of which the virus inoculated by tick-bite can circulate adequately to infect further ticks. Because tick populations are adequate only where suitable vegetation provides the appropriate microclimate, infections occur in restricted foci. Wild vertebrates do not usually show the disease, but can be infected and circulate virus only once because of antibody formation, and accordingly their population turnovers must supply enough new susceptibles annually. Movement of these viruses to new areas probably depends on the carriage of infected ticks by large mammals or migrant birds. A stable enzootic disease changes to epizootic or epidemic mainly because of population-changes in ticks or vertebrates, or introductions by man of domestic animals or introduction of virus to new areas.

A second febrile disease of sheep and cattle in Britain is tick-borne fever, which was discovered during the investigation of louping ill by Gordon 
et al. Hitherto tick-borne fever has been classified as a Rickettsia, but Dr. A. Foggie indicated that apart from the presence of an arthropod vector it has little in common with the true rickettsiae, such as those causing typhus and Rocky Mountain spotted fever. The forms seen in parasitized phagocytes have some resemblance to large viruses, and, under the phase-contrast microscope, the elementary bodies in morulæ have been seen in rapid Brownian movement, a phenomenon paralleled in colonies of psittacosis virus. While the organism had been provisionally named Rickettsia phagocytophilia, Dr. Foggie was of the opinion that it should now be included in the genus Cytoecetes, in so far as it morphologically resembles the type species $C$. microti, a tick-borne parasite of the polymorphs of voles in Massachusetts. Tick-borne fever is widespread, and an important point, made by Dr. MacLeod, was that in relation to 'inefficient' links in the bioconose through self d9-ticking, as in birds and some carnivores, transmission can occur by the second day after attachment of nymphs. Sheөp are a reservoir of infection for ticks for at least several weeks after subsidence of the reaction. Cattle and goats are susceptible, and cross-infectivity and cross-immunity tests by Dr. Foggie suggest that there may be specific differences between the bovine and ovine strains of the organism; a recently isolated strain from red deer was of similar infectivity to the sheep strain. The harmful effects of louping ill are aggravated by the presence of the tick-borne fever microorganism, as shown by Dr. Gordon's experiments in exposing susceptible sheep to natural infection with louping ill and tick-borne fever.

In the wider field of rickettsial infections and ticks, Prof. D. S. Bertram outlined the characteristics of rickettsial organisms as deduced by various workers from studies, including some by electron microscopy, on species of Rickettsia pathogenic to man. The significance of ticks in human tick-borne rickettsiosis was considered as well as comments on tick-borne Rickettsia-like organisms of veterinary interest. Prof. Bertram then illustrated that differentiation within the controversial assemblage of pathogenic and symbiotic organisms may benefit from electron microscopy, and that this technique presents an opportunity for fruitful re-examination of the fate of the different rickettsiae in their tick hosts.

Although tick pyæmia is constantly associated with an infestation of Ixodes ricinus, the tick does not appear to be a vector of the causal Staphylococcus. Dr. Foggie's observations show that Staphylococci of the same bacteriophage types as those found in tick pyæmia cases were found to be common commensals on the skin of lambs in both tick-free and tickinfested areas. Lambs in the neutropænic phase of tick-borne fever were shown to be a hundredfold more susceptible to the intravenous inoculation of Staphylococci than healthy lambs. The subcutaneous or intradermal inoculation of Staphylococci, either with or without an extract of tick salivary gland, or the feeding of ticks on heavily contaminated skin areas, failed to reproduce the disease in both normal and neutropænic lambs.

Piroplasmosis (redwater fever) in cattle in Britain is due to a piroplasm now believed to be distinct from Babesia bovis, and for which resuscitation of the earlier name of $B$. divergens is proposed. Dr. H. E. Shortt made the point that piroplasmosis is one of the major causes of morbidity and mortality in cattle, and as such has a serious effect in limiting the potential food supplies of man. So far as is known, ticks are the chief and very likely the only vector of this condition, and, although Africa is probably the most seriously affected continent, all parts of the world harbour both piroplasms and their tick-vectors. Our knowledge of the life-history of the piroplasms in the tick is still inadequate and Dr. Shortt, in describing the life-cycle of Babesia canis in Rhipicephalus, has made notable contributions to filling in many of the blanks. The possibility of the introduction into Britain of equine and canine piroplasmosis, transmitted by Dermacentor reticulatus on the continent, was made by Dr. MacLeod. The suggested occurrence of $B$. caballi in Britain cannot be ignored, and with the apparent establishment of $D$. reticulatus in south-west England, due probably to similar ecological requirements to those of $I$. ricinus, the wild and free-range ponies of Devon and Cornwall, and in the New Forest, may well be ecologically susceptible to devastation by one or both of these disease agents if they were introduced. Their susceptibility is more probable from the apparent catholicity of the vector-range of these piroplasms, as the latter have been transmitted experimentally by several tick species.

Man is normally insusceptible to infection, but as ticks are almost as ubiquitous as mosquitoes and in infested regions man is constantly exposed to their bites, the possibility of the tick acting as a reservoir of occult or inapparent parasites of man cannot be ignored. Prof. P. C. C. Garnham stated in this connexion that the removal of the spleen in man abolishes immunity and the occult parasites multiply and a fatal infection may ensue. The point was made that thousands, if not millions, of people living under rural conditions, and in contact with pastures, may harbour inapparent infections of Babesia, other piroplasms, or even certain tickborne viruses. Whether such a condition is harmless, even in poople possessing a spleen, is a subject being investigated further by Prof. Garnham.

Relapsing fever, a tropical disease associated with soft ticks, is transmitted by the bite and/or contamination of the bite wound by the coxal fluid which is produced by some species during feeding. Dr. G. A. Walton, in discussing human relapsing fever epidemiology in Eastern Africa, described the morphological, biological and distributional peculiarities of four species of Argasid ticks previously included under the name Ornithodoros moubata (Murray, 1877). The part played by each of them in the transmission of human relapsing fever was outlined with reference to the evolution of the East African domestic subspecies, and the decisive effect on local transmission of Borrelia duttoni by the feeding preferences of its races on one hand and the distribution and social behaviour of the native human races on the other. The existence and implications of immunity to the infection in man were illustrated in relation to minor and major human population movements and to other factors producing changes in the territorial incidence of the disease. Dr. M. G. R. Varma directed attention to the fact that, in an infected tick, spirochætes may be found in practically every organ; but the organs are not necessarily infected with the same frequency or to the same degree. Moreover, two spezies of spiro. chrtes may behave differently towards the same tick organ. Both the frequency and the degree of infection are connected with the method of transmission of spirochrtes. Thus it has been shown 
that the salivary glands of nymphs of Ornithodoros moubata are more heavily infected with Borrelia duttoni than are those of adults. There is also some evidence to show that infection of the salivary glands may die out in the course of time, so that old adults, apparently as a result of repeated feeds, rarely transmit the infection by bite.

Infection of the coxal glands in those species of ticks which do not produce any coxal fluid while feeding can have no importance in the transmission of spirochretes and such ticks transmit solely by the bite. Coxal fluid from such ticks has been shown to be non-infective although the glands themselves may be infected.

Continued experimental passage of the spirochætes through the vertebrate hosts may result in their failure to infect ticks successfully. However, by inoculating spirochætes directly into the hæmoccle, they are able to infiltrate the salivary glands and coxal glands and transmit the infection, suggesting that the gut may act as a partial barrier to the entry of spirochætes into the hæmocole.

Some knowledge of the nature of the food imbibed by ticks and the methods of acquiring it may be of significance in assessing the timing of the intake and introduction of blood pathogens from and to the host. Examination of sections of larval and nymphal ticks feeding on rat skin by Miss Evelyn Sutton and Dr. D. R. Arthur shows evidence that a process involving the intake and digestion of non-blood tissue occurs. Moreover, field observations of adult Ixodes ricinus feeding on cattle revealed that ticks of the same degree of engorgement range in colour from light yellow to greyish, especially in the earlier stages. These colour differences are a reflexion of the colour of the gut contents visible through the integument, and, as afterwards confirmed by spectrophotometric analysis, the darker coloured gut contains a high proportion of blood and the lighter coloured gut a predominance of non-blood fluids. The ingestion of blood-inhabiting pathogens by the tick may accordingly be delayed for some days and in some cases may not occur at all. In certain larvæ, particularly those with short penetrant ability, it may well be that the diet is exclusively one of non-blood digested tissues, in which event the ingestion and passage of blood-inhabiting pathogens are negligible.

One of the significant features in ticks and mites is the ability of their pathogens to pass transovarially from one generation to the next. Prof. Bertram discussed how this may happen in rickettsiae, Dr. Varma showed how it occurred in ticks infected with Borrelia duttoni and Col. Shortt mentioned the passage of $B$. canis through the ovum of Rhipicephalus. Transovarian transmission in ticks and mites may be either obligatory or incidental. Prof. Garnham stated that obligate transovarial transmission occurs in Karyolysus and in Rickettsia tsutsumagushi, whereas $B$. canis for example, as Shortt described, may either progress from adult to egg to larva (that is, trans. ovarial) or fromstage to stage. Viruses sometimes pass through the egg, and spirochrtes often are trans. mitted in this way, although the organism tends to become less virulent to the vertebrate host after such passage, and, if this is repeated for several generations, the progeny is eventually freed of infection. It has been suggested that ease of transovarial transmission in ticks may be related to the fact that only a single membrane separates the egg from the hæmocole, whereas in insects greater insulation against the entry of viruses and pathogens is afforded by the presence of three membranes.

The proceedings of the symposium will be published in full by the Zoological Society of London.

D. R. Arthur

\section{QUEEN ELIZABETH COLLEGE, LONDON}

\section{SIR JOHN ATKINS LABORATORIES}

$\mathrm{Q}$ UEEN ELIZABETH COLLEGE (University of London) was again honoured by a visit from H.M. Queen Elizabeth, the Queen Mother, Chancellor of the University of London, when, on May 9, she opened the new building on Campden Hill, the Sir John Atkins Laboratories. Her Majesty addressed members of the College and distinguished guests assembled outside the Laboratories, and then made a tour of the building, where she talked to a number of the staff and students who work there.

The building, designed by Messrs. Adams, Holden and Pearson, and erected by Messrs. Holland and Hannen and Cubitts.(G.B.), Ltd., is six storeys of brown Buckinghamshire facing bricks, with panels of cream bricks between the lines of windows, and reconstructed Portland stone dressings. It houses the Departments of Biology, Microbiology, and Nutrition, which moved from the main College building last autumn, and released much-needed space there for the expansion of other departments. On part of the top floor there is a self-contained Isotope Unit for the use of any department needing to work with radioactive materials.
The Nutrition Department was founded in 1954, following the establishment by the University of London of the degree of B.Sc. (Nutrition), still the only degree of its kind in the world. For the first six years it worked in very restricted quarters, in part of two prefabricated huts. Now it has an area of more than $12,000 \mathrm{sq}$. ft., and is the first university department in Britain to have been specially designed for teaching of and research in nutrition. In addition to a large laboratory for forty-two undergraduates and a smaller teaching laboratory for twelve advanced students, there is accommodation for twenty-two research workers, with ten animal rooms for the rats and mice used in studying nutritional problems. Already, with the aid of grants from the research councils, from research foundations and from various industrial organizations, it has been possible to add eight graduate research workers to the staff of the Department. From this beginning the College will go on advancing by research the science of nutrition, a science which has assumed a new importance in face of the imminent danger of food production and food distribution failing to keep pace 